\title{
Gastric Motility Changes in Capsaicin-Induced Cytoprotection in the Rat Stomach
}

\author{
Koji Takeuchi, Hiromichi Niida, Jiro Matsumoto, Koji Ueshima and Susumu Okabe \\ Department of Applied Pharmacology, Kyoto Pharmaceutical University, \\ Misasagi, Yamashina, Kyoto 607, Japan
}

Received Augrast 18, 1990 Accepted November 5, 1990

\begin{abstract}
We have examined the effect of orally administered capsaicin on gastric motility in the rat to investigate a possible relationship between motility change and cytoprotection induced by this agent. Capsaicin, given orally $(1-30 \mathrm{mg} / \mathrm{kg})$, dosedependently inhibited hemorrhagic band-like tesions induced by ethanol $(60 \%$ in 150 $\mathrm{mM} \mathrm{HCl}$. This protection was significantly mitigated by desensitization of afferent neurons following capsaicin pretreatment 2 weeks before the experiment, and it was also significantly attenuated by prior administration of indomethacin, but not by spantide. Intragastric administration of capsaicin $(30 \mathrm{mg} / \mathrm{kg}$ ) significantly inhibited gastric motility and increased the mucosal blood flow, but had no effect on the transmucosal potential difference of the stomach. These functional changes induced by capsaicin were also less marked in the afferent neuronal desensitized rat, and they were significantly attenuated by indomethacin but not by spantide. These results suggest that the mucosal protection by intragastric capsaicin may be associated with the inhibition of gastric motility and the increase of mucosal blood flow. These responses may be induced by activation of primary afferent neurons which are probably sensitized by endogenous prostaglandins.
\end{abstract}

Recent studies have shown that capsaicinsensitive primary afferent neurons participate in the mucosal defensive mechanism of the stomach (1-5). Ablation of these neurons leads to aggravation of gastric lesions in a variety of experimental ulcer models, while intragastric capsaicin protects the rat gastric mucosa against damage induced by various means including ethanol (3-5). Although Holzer et al. (5) suggested that the rise in mucosal blood flow may represent a primary mechanism of afferent nerve-mediated mucosal protection, the pathway underlying this protection is yet undefined.

We have previously reported that a variety of compounds inhibited gastric motility at their cytoprotective doses and proposed motility inhibition as a possible mechanism of gas- tric cytoprotection $(6-8)$. It is conceivable that relaxation of the stomach wall may lead to flattening of the foldings, resulting in a decrease of the mucosal vulnerability to irritants, and reduces the severity of mucosal damage. Yet, no study has examined the role of gastric motility change in the cytoprotective action of capsaicin.

In the present study, we thus examined the effects of intragastric capsaicin on gastric motility and mucosal blood flow in the rat and investigated the causal relationships of these responses to the protective action against ethanol damage.

\section{MATERIALS AND METHODS}

Male Sprague Dawley rats weighing 230- 
$250 \mathrm{~g}$ were used. The animals were deprived of food but allowed free access to tap water for $18 \mathrm{hr}$ prior to the experiments. All studies were performed using 5-12 rats per group under unanesthetized conditions, unless otherwise specified.

\section{General protocols}

The experiments were performed in the following four groups of rats: A, normal (saline); $B$, indomethacin pretreatment; $C$, spantide pretreatment; and $\mathrm{D}$, the desensitization of capsaicin-sensitive afferent neurons. For functional ablation of these afferent neurons, the animals were given capsaicin s.c. once daily for 3 consecutive days $(25,50,100 \mathrm{mg} / \mathrm{kg}) 2$ weeks prior to the experiment (4). All capsaicin injections were performed under ether anesthesia; and to counteract the respiratory impairment associated with capsaicin injection, the rats were pretreated with terbutaline $(0.1$ $\mathrm{mg} / \mathrm{kg}$, i.m.) and aminophylline $(10 \mathrm{mg} / \mathrm{kg}$, i.m.) before capsaicin injection. To check for the effectiveness of the treatment, a drop of a $0.1 \mathrm{mg} / \mathrm{ml}$ solution of capsaicin was instilled into one eye of each rat, and the protective wiping movements were counted as previously reported (5). Animals treated with capsaicin that showed any wiping movements were excluded from the study. In each group, the effects of capsaicin $(1-30 \mathrm{mg} / \mathrm{kg})$ given intragastrically on the motility and the mucosal blood flow were investigated, and they were correlated with the cytoprotective action of this agent. Indomethacin $(5 \mathrm{mg} / \mathrm{kg})$ or spantide $(10 \mu \mathrm{g} / \mathrm{kg})$ was given subcutaneously 30 min or intravenously $5 \mathrm{~min}$ before capsaicin treatment $(30 \mathrm{mg} / \mathrm{kg})$.

\section{Induction of lesions}

The animals were given $1 \mathrm{ml}$ of acidified ethanol $(60 \%$ in $150 \mathrm{mM} \mathrm{HCl})$ by gavage 30 min after oral administration of capsaicin (1$30 \mathrm{mg} / \mathrm{kg}$ ), and they were killed $1 \mathrm{hr}$ later under deep ether anesthesia. The stomachs were removed, inflated by injecting $8 \mathrm{ml}$ of $2 \%$ formalin, immersed in $2 \%$ formalin for 10 $\min$ to fix both the inner and outer layers of the gastric wall, opened along the greater curvature and examined for lesions under a dissecting microscope with a square grid ( $X$ 10). The area $\left(\mathrm{mm}^{2}\right)$ of each necrotic lesion was measured, summed per stomach and used as a lesion score. The person measuring the lesions did not know the treatment given to the animals.

\section{Determination of gastric motility}

Gastric motility was measured using a miniature balloon according to the previously published method (6). Briefly, under ether anesthesia, a balloon, the support catheter and another catheter for intragastric administration of drug were placed in the glandular stomach through an incision of the forestomach. They were pulled out through the abdominal incision and held in place by a ligature. The animals were then kept in Bollman cages, and gastric motility was monitored on a recorder (Unicorder, U-228) using a pressure transducer (Narco Tele Care, model 151-T) and polygraph (San-Ei, model 6M-72) for $3 \mathrm{hr}$ after complete recovery from anesthesia. Capsaicin $(30 \mathrm{mg} / \mathrm{kg}$ ) was given intragastrically through a catheter implanted in the forestomach after the motor activity had well-stabilized. Quantitation of gastric motility was performed by counting the number of contractions with amplitude of $15 \mathrm{cmH}_{2} \mathrm{O}$ or greater and by measuring the amplitude of each contraction (clear spike) over a 10-min period, determining the mean for these periods of each rat, and by calculating the mean $\pm S . E$. for each period from $5-8$ rats.

\section{Measurement of gastric mucosal blood flow}

Gastric mucosal blood flow was measured in the rat using Laser Doppler flowmetry (Advance, model ALF-2100) under anesthetized conditions induced by urethane $(1.25 \mathrm{~g} / \mathrm{kg}$, i.p.). The abdomen was incised, and the stomach was exposed and mounted on a Lucite chamber as described in a previous paper (9). The laser probe was then placed on the corpus mucosa, and the mucosal blood flow was monitored for $2 \mathrm{hr}$. Capsaicin $(30 \mathrm{mg} / \mathrm{kg}$ ) was 
topically applied to the chamber for $30 \mathrm{~min}$ after the basal blood flow had well-stabilized. The data are expressed as the percentage of basal values and presented as the mean \pm S.E. from 5 different rats. In this study, the transmucosal potential difference (PD) was measured together with mucosal blood flow, using two agar bridges, one was positioned in the chamber and the other in the abdominal cavity.

\section{Preparation of drugs}

Drugs used were capsaicin (Wako, Osaka), indomethacin, aminophylline, terubutaline (Sigma Chemicals, St. Louis, MO), spantide ([D-arg ${ }^{1}$ D-Trp ${ }^{7.9}$, Leu $\left.{ }^{11}\right]$-substance P; Peptide Institute Inc., Osaka) and urethane (Nacalaj Tesque, Kyoto). Capsaicin was suspended in $0.5 \%$ carboxymethylcellulose (CMC) solution, while indomethacin was suspended in saline with a trace of Tween 80 (Wako). Each drug was prepared immediately before use and given p.o. and s.c. in a volume of $0.5 \mathrm{ml}$ per
$100 \mathrm{~g}$ body wt. or i.v. and i.m. in a volume of $0.2 \mathrm{ml}$ per $100 \mathrm{~g}$ body wt.

\section{Statistics}

Data are presented as the mean \pm S.E. from 5 to 12 rats per group. Statistical analysis was performed using a two-tailed Dunnett's multiple comparison test (10), and values of $P$ $<0.05$ were regarded as significant.

\section{RESULTS}

\section{Effects of capsaicin on ethanol-induced gastric damage}

Oral administration of ethanol (60\% in 150 mM HCl) produced hemorrhagic band-like lesions in the glandular portion, along the long axis of the stomach. These lesions were dosedependently prevented by p.o.-administered capsaicin $(1-30 \mathrm{mg} / \mathrm{kg})$, and a significant effect was observed at $3 \mathrm{mg} / \mathrm{kg}$ or greater; the reductions were $73.5 \%$ and $92.7 \%$ at 10 and $30 \mathrm{mg} / \mathrm{kg}$, respectively (Fig. 1). The mucosal

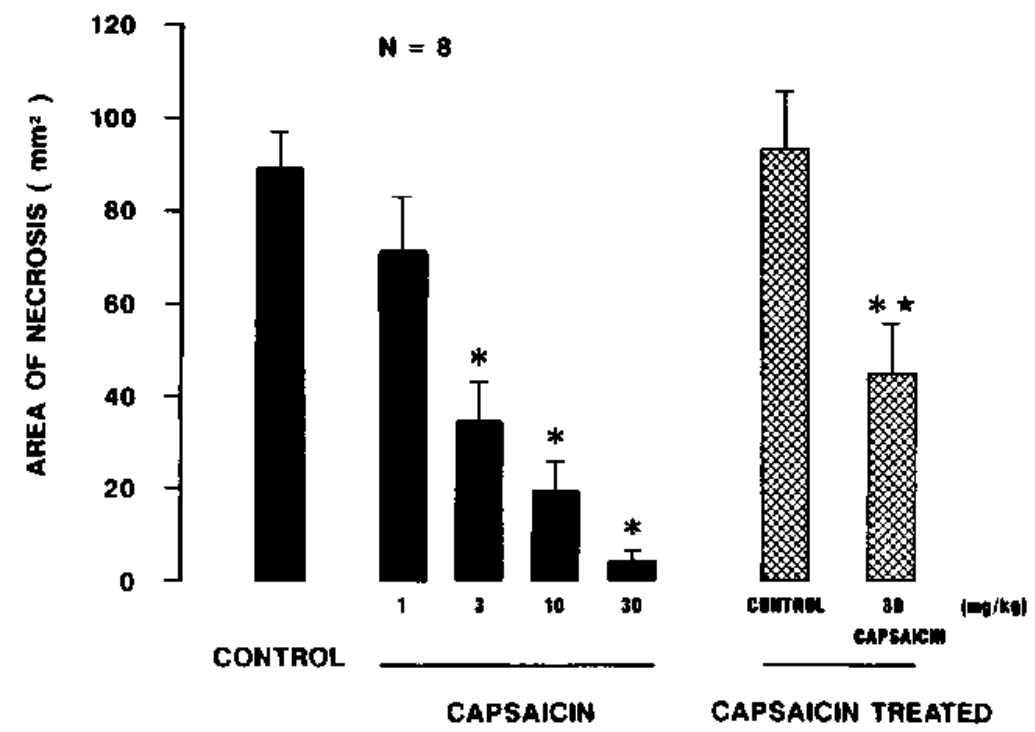

Fig. 1. Effects of capsaicin $(1-30 \mathrm{mg} / \mathrm{kg})$ on gastric lesions induced by ethanol $(1 \mathrm{ml}, 60 \%$ in $150 \mathrm{mM}$ $\mathrm{HCl}$ ) in the rat. In the left panel, capsaicin was given p.o. 30 min before administration of ethanol in normal rats, while in the right panel, this agent was given p.o. to the rats after desensitization of afferent neurons. The afferent neuronal desensitization was performed by consecutive injections of capsaicin 2 weeks prior to the experiment. Data are presented as the mean $\pm S$.E. from 8 rats. * . *: Statistically significant difference from the corresponding controls or the group given $30 \mathrm{mg} / \mathrm{kg}$ of capsaicin under normal conditions, respectively, at $\mathbf{P}<0.05$. 
response to ethanol was not significantly affected by desensitization of afferent neurons following capsaicin pretreatment (s.c.). However, the protective action of p.o.-capsaicin was mitigated in the animals when the primary afferent neurons had been desensitized; the degree of protection afforded by 30 $\mathrm{mg} / \mathrm{kg}$ of capsaicin was $47.3 \%$ in the capsaicin-pretreated rats, which is significantly lower than that $(92.7 \%)$ observed in normal rats. The protective action of capsaicin ( 30 $\mathrm{mg} / \mathrm{kg}$ ) was also significantly attenuated by prior administration of indomethacin (5 $\mathrm{mg} / \mathrm{kg}$, s.c. $)$ but not by spantide $(10 \mu \mathrm{g} / \mathrm{kg}$, i.v.) (Fig. 2). Indomethacin almost totally attenuated the protective effect of capsaicin; the inhibition against ethanol damage was $12.4 \%$ in the presence of indomethacin, which is significantly lower when compared to that (74.8\%) induced by capsaicin in the absence of this agent.

\section{Effects of capsaicin on gastric motor activity}

The stomachs of normal rats contracted at a frequency of $16-20 / 10 \mathrm{~min}$ with an amplitude

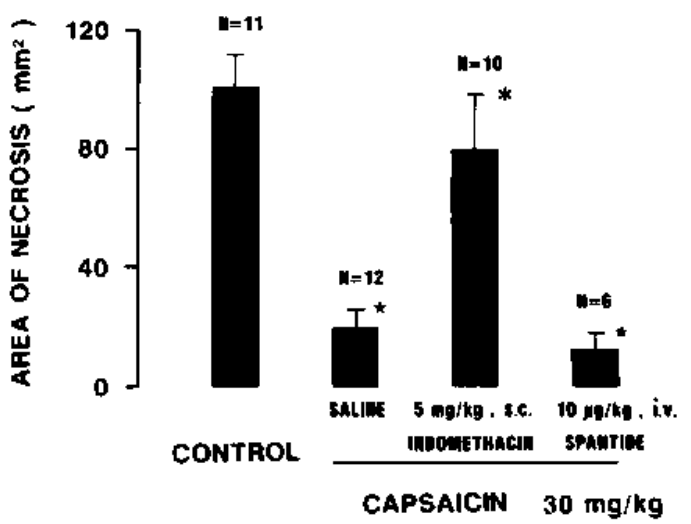

Flg. 2. Effects of indomethacin (5 mg/ $\mathrm{kg}$ ) and spantide $(10 \mu \mathrm{g} / \mathrm{kg})$ on the protective action of capsaicin against ethanol in the rat. Capsaicin $(30 \mathrm{mg} / \mathrm{kg})$ was given p.o. $30 \mathrm{~min}$ before ethanol treatment. Indomethacin (s.c.) or spantide (i.v.) was given $30 \mathrm{~min}$ or $5 \mathrm{~min}$ before administration of capsaicin, respectively. Data are presented as the mean \pm S.E. from 6-12 rats. *.*: Statistically significant difference from the control or saline plus capsaicin group, respectively, at $P<0.05$. of $18.6 \pm 3.2 \mathrm{cmH}_{2} \mathrm{O}$. Intragastric administration of capsaicin $(30 \mathrm{mg} / \mathrm{kg})$ significantly inhibited gastric motility for about $1 \mathrm{hr}$; the inhibition of the amplitude of contraction was $70 \%$ at 30 -min post treatment (Figs. 3 and 4). Capsaicin action on the motility was, however, significantly less effective in the animals after desensitization of afferent neurons, and a significant inhibition was observed only for 20 min. Functional ablation of the afferent neurons by itself did not significantly alter spontaneous motor activity. Pretreatment with indomethacin $(5 \mathrm{mg} / \mathrm{kg}$, s.c.) also significantly mitigated the inhibitory action of intragastric capsaicin on gastric motility, although this agent alone at this dose had no effect on the spontaneous contractile activity. In these animals, the inhibitory effect of capsaicin was

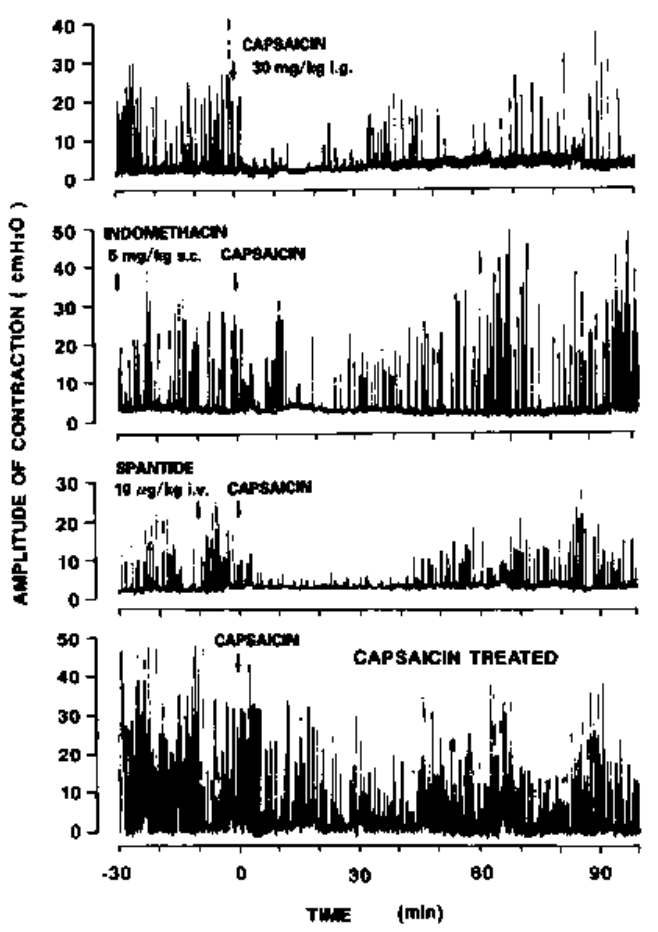

Fig. 3. Representative recordings of gastric motility after intragastric administration of capsaicin ( 30 $\mathrm{mg} / \mathrm{kg})$ in the rats. Indomethacin $(5 \mathrm{mg} / \mathrm{kg}, \mathrm{s.c}$.) or spantide $(10 \mu \mathrm{g} / \mathrm{kg}$, i.v.) was given $30 \mathrm{~min}$ or $5 \mathrm{~min}$ before capsaicin treatment. In the lowest panel, the animals were pretreated with capsaicin 2 weeks prior to the experiment for ablation of afferent neurons. 
reduced in both the potency and duration as compared to control rats without indomethacin treatment, and the amplitude of contractions became rather significantly greater at 1 hr after administration of capsaicin (Fig. 5). When the animals were pretreated with spantide $(10 \mu \mathrm{g} / \mathrm{kg}$, i.v.), the capsaicin effect on the motility was rather potentiated, resulting in about $80 \%$ inhibition of the contractile responses for $50 \mathrm{~min}$.

Effects of capsaicin on gastric mucosal blood flow and potential difference

The mucosal blood flow determined by La-

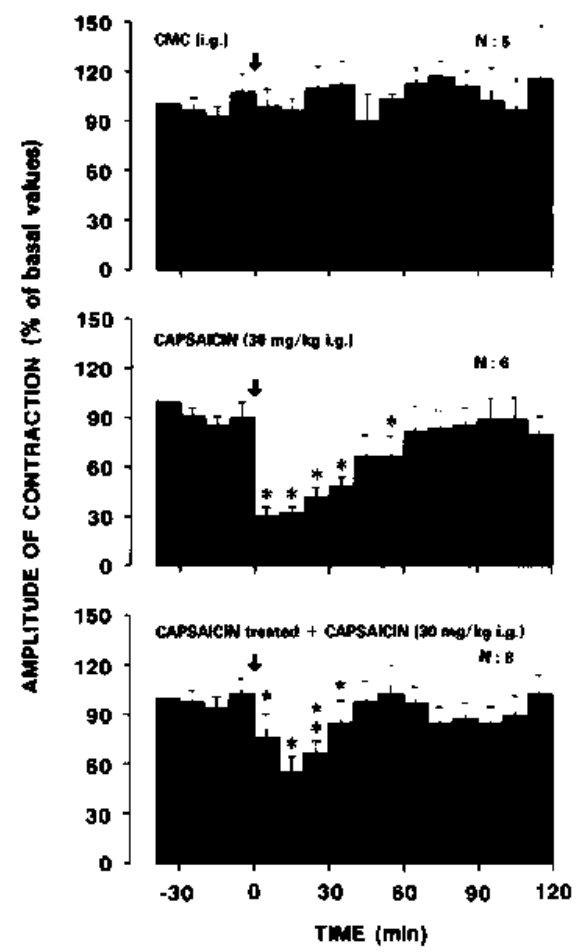

Fig. 4 Effects of capsaicin on gastric motility in the rat. Capsaicin $(30 \mathrm{mg} / \mathrm{kg})$ was given intragastrically through a catheter implanted in the forestomach. In the lowest panel, the animals were pretreated with capsaicin 2 weeks prior to the experiment for ablation of primary afferent neurons. Data are expressed as the percentage of the hasal values (amplitude) and represent the mean $\pm \mathrm{S}$.E. from $5-8$ rats. ${ }^{*}, \star$ : Statistically significant difference from the control rats given CMC or the normal rats given capsaicin, respectively, at $P<0.05$. ser flowmetry was $13-17 \mathrm{ml} / \mathrm{min} / 100 \mathrm{~g}$ tissue in normal rats under anesthetized conditions. The gastric mucosa responded to topical application of capsaicin $(30 \mathrm{mg} / \mathrm{kg}$ ) for $30 \mathrm{~min}$ by a significant and persistent increase of the mucosal blood flow for $90 \mathrm{~min}$ (Figs. 6 and 7). The increased blood flow responses caused by capsaicin were almost completely attenuated by prior administration of indomethacin ( 5 $\mathrm{mg} / \mathrm{kg}$, s.c.), resulting in the fluctuation around the baseline levels. The desensitization of capsaicin-sensitive afferent neurons did not alter the levels of the mucosal blood flow (15.4 $\pm 2.1 \mathrm{ml} / \mathrm{min} / 100 \mathrm{~g}$ tissue), but significantly inhibited an increase of the blood flow

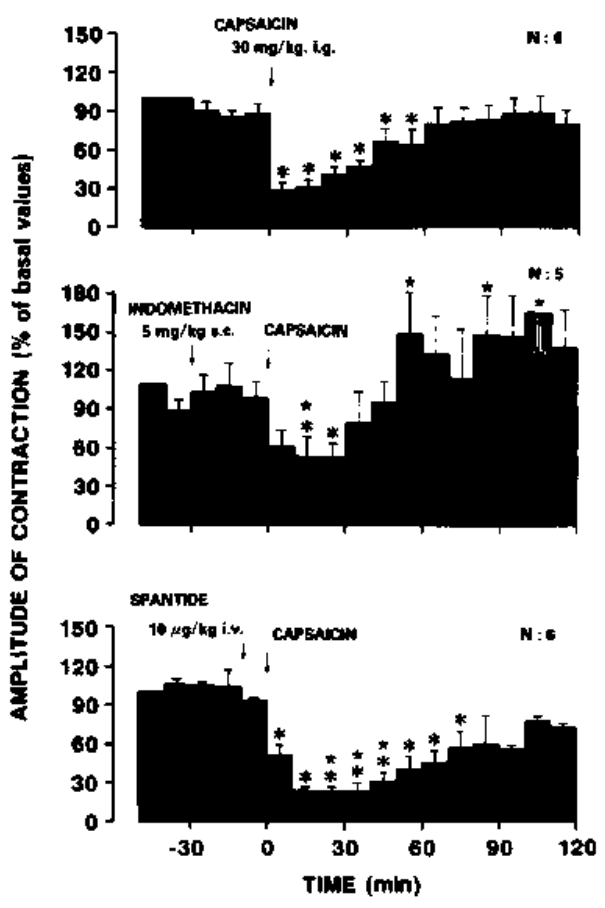

Fig. 5 Effects of indomethacin ( $5 \mathrm{mg} / \mathrm{kg}$, s.c.) and spantide $(10 \mu \mathrm{g} / \mathrm{kg}$, i.v.) on the inhibitory action of capsaicin $(30 \mathrm{mg} / \mathrm{kg}$, i.g.) on gastric motility in the rat. Indomethacin or spantide was given 30 min or 5 min before capsaicin treatment. respectively. Data are expressed as the percentage of basal values (amplitude) and represent the mean $\pm S$.E. from 5-6 rats. *, Statistically significant difference from basal values in each group or the corresponding values in the saline plus capsaicin group, respectively, at $\mathbf{P}<0.15$. 


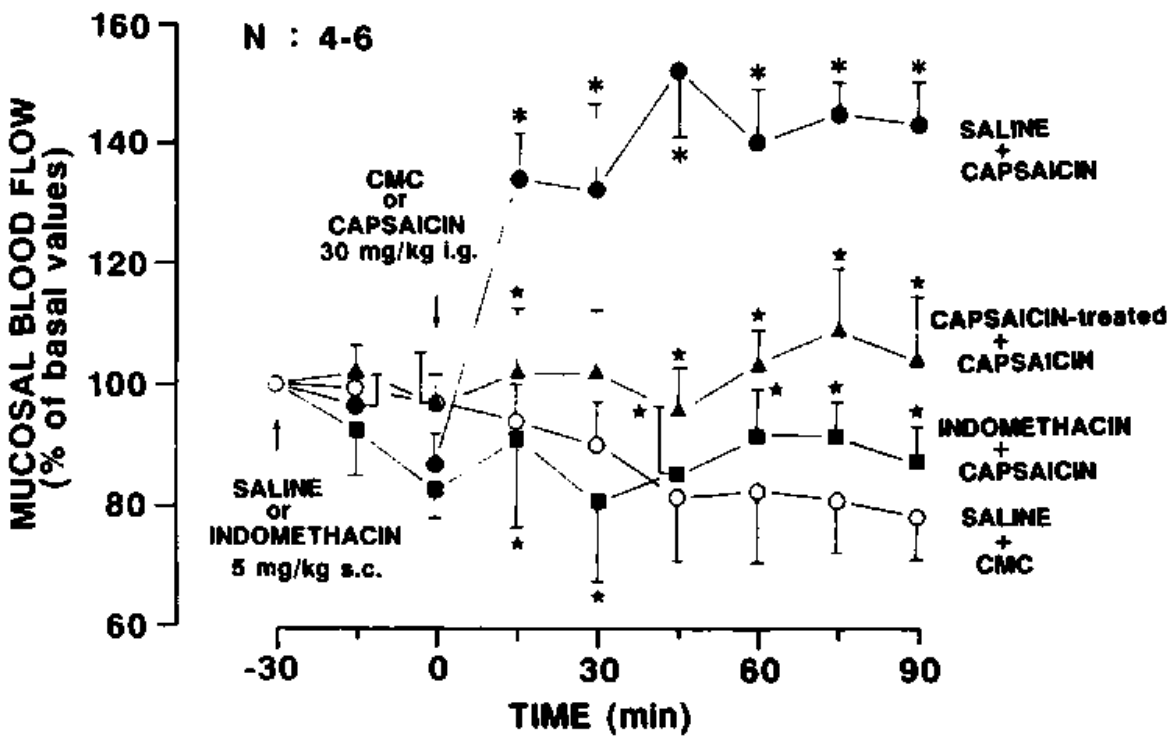

Fig. 6. Effects of capsaicin on gastric mucosal blood flow in the normal or afferent neuronal desensitized rats under anesthetized conditions. Capsaicin $(30 \mathrm{mg} / \mathrm{kg}$ ) was applied topically to the mucosa mounted on the Lucite chamber. Desensitization of afferent neurons was done by consecutive injection of capsaicin for 3 days 2 weeks prior to the experiment. Indomethacin $(5 \mathrm{mg} / \mathrm{kg}$ ) was given s.c. to the normal rat $30 \mathrm{~min}$ before application of capsaicin. Data are expressed as the percentage of basal values and represented as the mean \pm S.E. from 4-6 rats. ${ }^{*}$ : Statistically significant difference from the saline plus CMC group or the saline plus capsaicin group, respectively, at $\mathbf{P}<\mathbf{0 . 0 5}$.

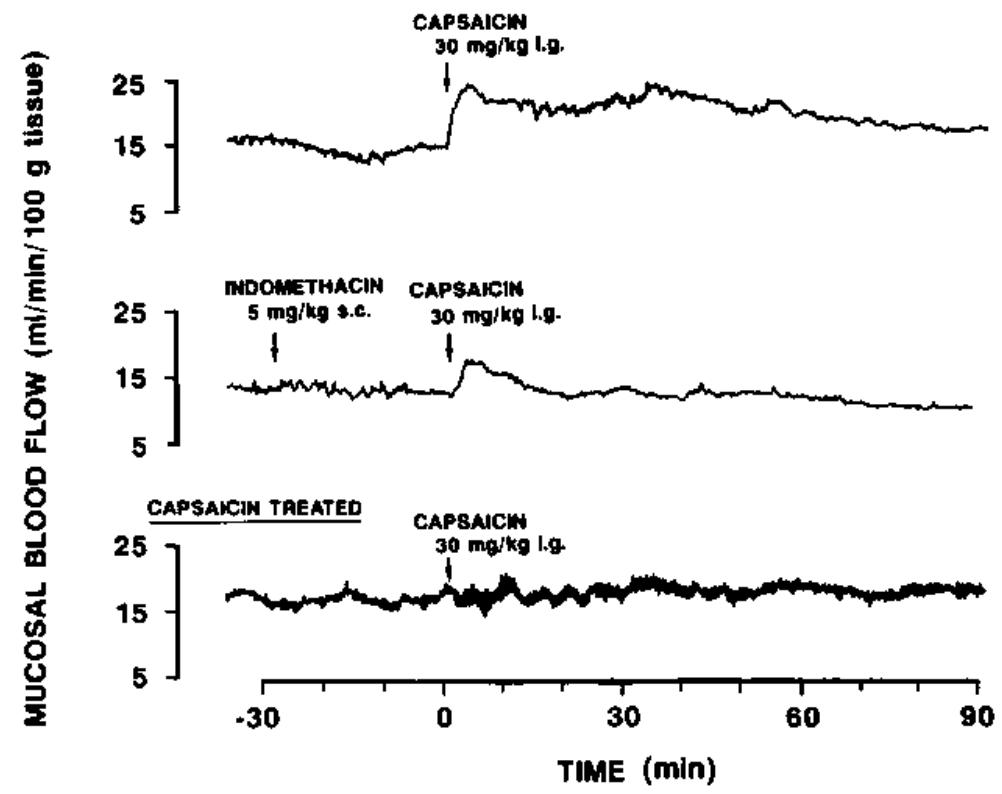

Fig. 7. Representative recording of the mucosal blood flow responses induced by capsaicin in the anesthetized rat. Capsaicin $(30 \mathrm{mg} / \mathrm{kg})$ was topically applied to the mucosa mounted on the Lucite chamber. For the detailed protocols, refer to Fig. 6. Note that the increased blood flow responses to capsaicin were totally attenuated by indomethacin $(5 \mathrm{mg} / \mathrm{kg}$, s.c.) or ablation of the afferent neurons. 
in response to mucosal application of capsaicin. On the other hand, the transmucosal PD of the stomach varied from $-30 \mathrm{mV}$ to $-35 \mathrm{mV}$ (mucosal negative) and remained in this range during a test period. In the control experiment where the mucosa was exposed to the vehicle $(0.5 \% \mathrm{CMC})$ for $30 \mathrm{~min}$, the $\mathrm{PD}$ was elevated during the application, but quickly returned to baseline levels after removal of the agent (Fig. 8). Mucosal application of capsaicin $(30 \mathrm{mg} / \mathrm{kg})$ produced similar PD changes as those induced by the vehicle, and the values of PD after removal of capsaicin $(-35.6 \pm 1.1 \mathrm{mV})$ were not significantly different from those observed before the application $(-33.3 \pm 1.2 \mathrm{mV})$.

\section{DISCUSSION}

Capsaicin, the pungent principle of hot red pepper, causes a selective ablation of peptidecontaining primary afferent neurons and has been used as an experimental probe to activate these nerve endings in the stomach (1113). The present study confirmed the protective action of intragastric capsaicin against
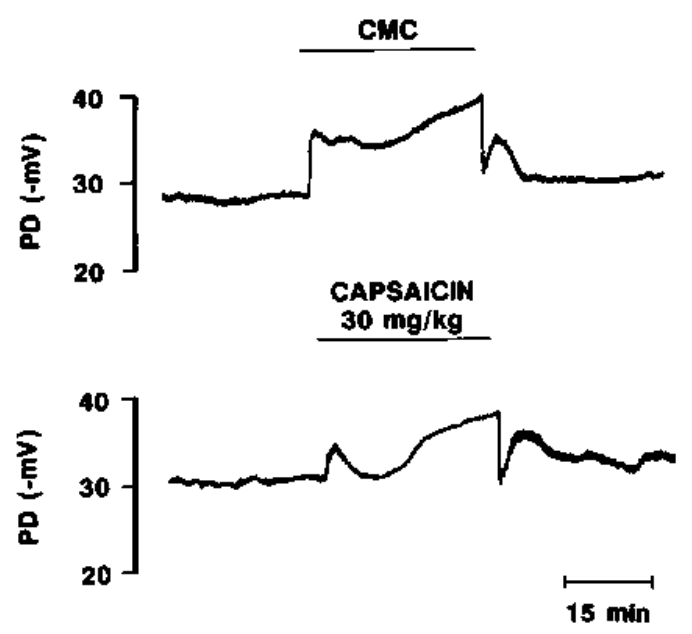

Fig. 8. Representative figures showing the PD responses induced by capsaicin in the anesthetized rat. Capsaicin ( $30 \mathrm{mg} / \mathrm{kg}$ ) or $0.5 \% \mathrm{CMC}$ was topically applied to the mucosa mounted on the Lucite chamber, and the PD was continuously monitored before, during and after the application. ethanol $(3,5)$ and further demonstrated that this agent significantly inhibits gastric motility at the cytoprotective dose, providing more evidence for a relationship between motility inhibition and gastric cytoprotection.

In agreement with the findings by others (3, 4), we observed that intragastric capsaicin significantly reduced the severity of gastric lesions induced by ethanol. The degree of capsaicin protection was, however, much higher than that reported by Holzer et al. $(3,5)$. This may be explained by the different ways of drug preparation and dosing used in these two experiments. They prepared capsaicin solution by using Tween 80 plus ethanol and perfused the stomach with capsaicin at the maximal concentration of $640 \mu \mathrm{M}(\sim 0.2 \mathrm{mg} / \mathrm{ml})$, while in our study, capsaicin was suspended with $0.5 \% \mathrm{CMC}$ and administered p.o. in doses of $1-30 \mathrm{mg} / \mathrm{kg}$. On the other hand, the protective action of capsaicin was significantly mitigated by prior administration of indomethacin and was impaired by primary afferent neuronal desensitization following capsaicin pretreatment. The latter may suggest that intragastric capsaicin induces gastric cytoprotection by activating these afferent neurons in the stomach $(2-5)$. In the present study, desensitization of these neurons itself did not significantly affect the formation of ethanol-induced lesions as well as gastric functions, while others reported a potentiation of the lesions following the sensory denervation $(5,14)$. The reason for this discrepancy remains unknown, but it may be due to different experimental conditions; we used $60 \%$ ethanol in $150 \mathrm{mM} \mathrm{HCl}$ to induce gastric lesions, while others provoked the lesions by $100 \%$ ethanol or by perfusing the stomach with $25 \%$ ethanol for $1 \mathrm{hr}$.

Attenuation by indomethacin of the capsaicin effect appeared to disagree with the previous observation that intragastric capsaicin did not alter the ex vivo formation of $\mathrm{PGE}_{2}$ in the gastric mucosa (5). PGs locally generated by tissue trauma have long been recognized as activating nociceptive afferent neurons (15, 16). It might be possible that endogenous PGs sensitize the afferent neurons to stimulation by 
intragastric capsaicin, resulting in potentiation of the mucosal protection mediated by capsaicin-sensitive afferent neurons. A recent study by Esplugues and Whittle (17) even showed the involvement of local sensory neurons in the protective process of $\mathrm{PGE}_{2}$. Thus, attenuation by indomethacin of the capsaicin-induced mucosal protection and failure of this agent to increase PG synthesis would be understandable based on the above contention. Yet, the mode of capsaicin-induced mucosal protection is different from the adaptive cytoprotection, certain types of which seem to be mediated by PGs and accompanied by a reduction of the PD of the stomach (18). In fact, capsaicin itself is devoid of any irritative action on the gastric mucosa, inasmuch as this agent had no effect on transmucosal PD of the stomach.

The present study clearly showed that intragastric capsaicin significantly inhibited gastric motility at the cytoprotective dose. In addition, this effect was also impaired by either indomethacin pretreatment or desensitization of the capsaicin-sensitive afferent neurons, indicating that the motility effect of intragastric capsaicin is paralleled by a reduction in gross mucosal injury. These results support our previous observation that a variety of compounds showed cytoprotection at the doses that inhibit gastric motility $(6-8)$. Inhibition of gastric motility may lead to flattening of the mucosal foldings and decreases the mucosal vulnerability to irritants, resulting in prevention of the fold-related band-like lesions $(8,19)$. Thus, the present results provide further evidence suggesting a close relationship between motility inhibition and gastric cytoprotection.

On the other hand, activation of capsaicinsensitive afferent neurons enhances blood flow in a variety of somatic tissues (14). In fact, intragastric capsaicin produced a marked and sustained increase of mucosal blood flow, in agreement with the findings by others that capsaicin is able to enhance the gastric clearance of aminopyrine and aniline $(20,21)$. Since this response was attenuated by indomethacin and desensitization of afferent neurons, similar to the motility response, the same mechanism might operate in these two responses induced by capsaicin. It is known that ethanol-induced mucosal injury is accompanied by blood flow changes such as stasis or congestion (22). Holzer et al. (5) reported that the rise in blood flow represents a primary mechanism of afferent nerve-mediated mucosal protection. At the present stage of research, we cannot dissociated these two responses in the causal relationship to the mucosal protection induced by capsaicin. However, since norepinephrine exhibited gastric cytoprotection and motility inhibition, despite producing a reduction of mucosal blood flow (18), the motility inhibition may be commonly associated with the phenomenon of cytoprotection.

The functional changes seen after intragastric administration of capsaicin appear to be brought about by a local release of transmitters such as substance $P$ or calcitonin generelated peptide (CGRP) $(11,13)$. Unlike the substance $\mathbf{P}$ gastric innervation, which mainly derives from intrinsic neurons, most of the gastric CGRP originates from the spinal sensory neurons. The present results exclude the possibility that substance $P$ is a possible mediator of afferent nerve-mediated gastric protection, since spantide, a substance $P$ antagonist, had no effect on capsaicin-induced cytoprotection and motility changes. This is consistent with the findings by others that CGRP may be a local mediator of afferent nerve-induced vasodilation and mucosal protection $(23,24)$.

Taken together, the present study showed for the first time that intragastric capsaicin inhibits gastric motility at the cytoprotective dose, probably by activating primary afferent neurons in the stomach, and supports our proposal that the motility inhibition may be associated with the phenomenon of gastric cytoprotection. The mechanism may also involve endogenous PGs which might sensitize these neurons to capsaicin, although it remains undefined how capsaicin-sensitive afferent neurons and PGs interact in this process and what is the site of this interaction. 


\section{REFERENCES}

1 Szollcsanyi, J. and Bartho, L.: Impaired defense mechanism to peptic ulcer in the capsaicin-desensitized rat. In Gastro-intestinal Defense Mechanisms, Edited by Mozik, G.Y., Hanninen, O. and Javor, T., p. 39-51, Pergamon Press and Akademiaki Kiado, Oxford and Budapest (1981)

2 Holzer, P. and Sametz, W.: Gastric mucosal protection against ulcerogenic factors in the rat mediated by capsaicin-sensitive neurons. Gastroenterology 91, 975-981 (1986)

3 Holzer, P. and Lippe, I.T.: Stimulation of afferent nerve endings by intragastric capsaicin protects against ethanol-induced damage of gastric mucosa. Neuroscience 27, 981 -987 (1988)

4 Holzer, P., Pabst, M.A. and Lippe, I.T.: Intragastric capsaicin protects against aspirin-induced lesion formation and bleeding in the rat gastric mucosa. Gastroenterology 96, 1425 - 1433 (1989)

5 Holzer, P., Pabst, M.A., Lippe, I.T., Peskar, B.M., Peskar, B.A., Livingston, E.H. and Guth, P.H.: Afferent nerve-mediated protection against deep mucosal damage in the rat stomach. Gastroenterology 98, 838-848 (1990)

6 Takeuchi, K., Nishiwaki, H. and Okabe, S.: Cytoprotective action of mast cell stabilizers against ethanol-induced gastric lesions in rats. Japan. J. Pharmacol. 42, 297-307 (1986)

7 Takeuchi, K., Nishiwaki, H., Okada, M. and Okabe, S.: Mucosal protective action of histamine against gastric lesions induced by $\mathbf{H C l}$ in rats: $\mathbf{I m}$ portance of antigastric motor activity mediated by $\mathrm{H}_{2}$-receptors. J. Pharmacol. Exp. Ther. 245, 632638 (1988)

8 Takeuchi, K., Okada, M., Niida, H. and Okabe, S.: Role of sulfhydryls in mucosal injury caused by ethanol: Relation to microvascular permeability, gastric motility and cytoprotection. J. Pharmacol. Exp. Ther. 248, 836-841 (1989)

9 Takeuchi, K., Ishihara, Y., Okada, M., Niida, H. and Okabe, S.: A continuous monitoring of mucosal integrity and secretory activity in rat stomach: A preparation using a Lucite chamber. Japan. J. Pharmacol. 49, 235-244 (1989)

10 Dunnett, C.W.: A multiple comparison procedure for comparing several treatments with a control. J. Am. Stat. Assoc. 50, 1096-1121 (1955)

11 Sharkey, K.A., Williams, R.G. and Dockray, G.J.: Sensory substance $P$ innervation of the stomach and pancreas: Demonstration of capsaicinsensitive sensory neurons in the rat by combined immunohistochemistry and retrograde tracing.
Gastroenterology 87, 914-921 (1984)

12 Buck, S.H. and Burks, T.F.: The neuropharmacology of capsaicin: Review of some recent observations. Pharmacol. Rev. 38, 179-226 (1986)

13 Green, T.M. and Dockray, G.J.: Characterization of the peptidergic afferent innervation of the stomach in the rat, mouse and guinea pigs. Neuroscience 25, 181- 193 (1988)

14 Esplugues, J.V. and Whittle. B.J.R.: Morphine potentiation of ethanol-induced gastric mucosal damage in the rat: Role of local sensory afferent neurons. Gastroenterology 98, 82 -89 (1990)

15 Lundberg, J.M. and Saria, A.: Polypeptide-containing neurons in airway smooth muscle. Anal. Rev. Physiol. 49, 557-572 (1987)

16 Yonei, Y., Holzer, P. and Guth, P.H.: Laparotomy-induced gastric protection against ethanol injury is mediated by capsaicin-sensitive sensory neurons. Gastroenterology 99, 3-9 (1990)

17 Esplugues, J.V. and Whittle, B.J.R.: Prostaglandin protection of the rat gastric mucosa is attenuated by opioids. Gastroenterology 99, A-42 (1990)

18 Takeuchi, K., Ohno, T. and Okabe, S.: Irritative and protective activity of mild irritants in rat stomach. Dig. Dis. Sci. 32, 889-896 (1987)

19 Takeuchi, K., Nishiwaki, H. and Okabe, S.: Effects of dopamine on gastric mucosal lesions induced by ethanol in rats: Possible involvement of antigastric motor activity mediated by alpha $a_{2}$ adrenoceptors. Dig. Dis. Sci. 33, 1560-1568 (1988)

20 Limlomwongse. L., Chaitauchawong, C. and Tongyai, S.: Effect of capsaicin on gastric acid secretion and mucosal blood flow in the rat. J. Nutr. $109,773-777$ (1979)

21 Lippe, I.T., Pabst, M.A. and Holzer, P.: Intragastric capsaicin enhances rat gastric acid elimination and mucosal blood flow by afferent nerve stimulation. Br. J. Pharmacol. 96, 91-100 (1989)

22 Guth, P.H., Paulsen, G. and Nagata, H.: Histologic and micro-circulatory changes in alcoholinduced gastric lesions in the rat: Effect of prostaglandin cytoprotection. Gastroenterology 87, 1083 -1090 (1984)

23 Holzer, P., Tache, Y. and Guth, P.H.: The vasodilator neuropeptides, CGRP and VIP but not substance $P$ and neurokinin $A$, increase rat gastric mucosal blood flow. Gastroenterology 99, (abstract) A-175 (1990)

24 Robert, A., Olafsson, A.S., Lancaster, C. and Gilbertson-Beardling, S.: Acute capsaicin inhibits aspirin ulcers and acid secretion in rats, but capsaicin denervation had no effect. Gastroenterology 99, (abstract) A-113 (1990) 